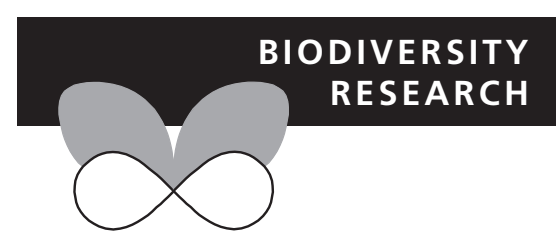

\title{
Stable-hydrogen isotope measures of natal dispersal reflect observed population declines in a threatened migratory songbird
}

\author{
Colin E. Studds ${ }^{1}$, Kent P. McFarland ${ }^{2}$, Yves Aubry ${ }^{3}$, Christopher C. \\ Rimmer $^{2}$, Keith A. Hobson ${ }^{4}$, Peter P. Marra ${ }^{1}$ and Leonard I. Wassenaar ${ }^{4}$
}

${ }^{1}$ Smithsonian Conservation Biology Institute, Migratory Bird Center, National Zoological Park, Washington, DC, 20008, USA,

${ }^{2}$ Vermont Center for Ecostudies, Norwich, VT, 05055, USA, ${ }^{3}$ Environment Canada, Québec, G1J 0C3, Canada, ${ }^{4}$ Environment Canada, Saskatoon, SK S7N 3H5, Canada

*Correspondence: Colin E. Studds, University of Queensland, School of Biological Sciences, Brisbane, Qld, 4072, Australia E-mail: c.studds@uq.edu.au

\begin{abstract}
Aim Measuring dispersal is crucial for estimating demographic rates that inform conservation plans for rare and threatened species. We evaluated natal dispersal patterns in Bicknell's thrush (Catharus bicknelli) across most of the breeding range using a 10-year data set of stable-hydrogen isotope ratios in feathers $\left(\delta^{2} \mathrm{H}_{F}\right)$ grown on the natal area and sampled 1 year later at the first breeding site.
\end{abstract}

Location North-eastern United States and south-eastern Canada.

Methods We used $\delta^{2} \mathrm{H}_{F}$ values of adult thrushes sampled at 25 breeding sites as prior information for assigning first-time breeders to their natal site. We calculated the minimum distance birds moved from their natal to first breeding site and fit these data to three statistical distributions for characterizing the importance of long-distance dispersal: the exponential, Weibull and half-Cauchy. Finally, we assessed differences in the probability of dispersal across the breeding range and through time to understand spatio-temporal variation in demographic connectivity.

Results The $\delta^{2} \mathrm{H}_{F}$ values of first-time breeders were lower compared with those of adults, a difference that was greater at the southern compared with northern breeding range extreme. Assignment tests accounting for age differences in $\delta^{2} \mathrm{H}_{F}$ suggested that most birds dispersed $<200 \mathrm{~km}$ from their natal area and within the centre of the breeding range, whereas comparatively few individuals dispersed up to $700 \mathrm{~km}$. A Weibull distribution provided the best fit to these data. Two of three corrections for age differences in $\delta^{2} \mathrm{H}_{F}$ indicated that natal dispersal probability declined by 30-38\% from 1996 to 2005 .

Main conclusions Our findings suggest that estimating natal dispersal with $\delta^{2} \mathrm{H}_{F}$ measurements may contribute to understanding the resilience of geographically isolated Bicknell's thrush populations. Declining natal dispersal may be symptomatic of observed population declines and could compound this trend by limiting demographic exchange between habitat patches predicted to be increasingly isolated by natural and anthropogenic habitat changes.

\section{Keywords}

Bicknell's thrush, conservation biogeography, dispersal, movement ecology, Neotropical-Nearctic migratory bird, population declines, stable isotopes. 


\section{INTRODUCTION}

Dispersal plays a fundamental role in many ecological and evolutionary processes. In recent years, theoretical models have focused on the importance of dispersal for metapopulation persistence (Ovaskainen \& Hanski, 2004), metacommunity structure (Leibold et al., 2004) and range expansion (Phillips et al., 2010). Despite these contributions, dispersal remains one of the most poorly understood life history traits because the complete distribution of dispersal distances is so difficult to measure empirically. Common methods, such as markrecapture techniques, are useful for documenting relatively short-distance dispersal, but are poorly suited to detecting long-distance dispersal beyond study area boundaries (Koenig et al., 1996; Nathan et al., 2003). Overcoming this limitation is an important challenge in applied ecology because longdistance dispersal estimates are key to understanding how organisms will respond to habitat loss and other environmental changes (Trakhtenbrot et al., 2005). Quantifying dispersal estimates is especially important for rare or threatened species whose persistence may depend in part on movement dynamics among isolated habitat patches.

Although long-distance dispersal comprises a small fraction of the overall dispersal distribution, it can have a disproportionate effect on the genetic structure and dynamics of populations (Hanksi, 1999; Clobert et al., 2001). Dispersal is probably the most important contributor to gene flow; thus, long-distance dispersal plays a central role in determining the scale of local adaptation and the extent of genetic variation among subpopulations (Lenormand, 2002). Longdistance dispersal facilitates colonization of new habitats during range expansion, particularly when the distribution of suitable habitat is patchy or ephemeral. Importantly, even when long-distance dispersal rates are sufficient to promote genetic mixing, they may be too low to prevent subpopulations from functioning as demographically discreet units with divergent growth trajectories (Lowe \& Allendorf, 2010). Long-distance dispersal also can be a key determinant of whether species undergo range shifts as part of an adaptive response to land cover change or other environmental disturbances that alter the availability of suitable habitat on the landscape (Wiegand et al., 1999; Trakhtenbrot et al., 2005).

In many animal species, natal dispersal distances exceed those of adults (Gaines \& McClenaghan, 1980; Paradis et al., 1998; Semlitsch, 2008). For adults, fidelity to breeding sites may enhance future reproductive success through the acquisition of social information about local habitat suitability or conspecific competitors (Doligez et al., 2002; Nocera et al., 2006). Although juveniles might also benefit from breeding in familiar locations near the natal site, several life history constraints are thought to favour natal dispersal. For example, females of many bird species may disperse away from the natal site to reduce the risk of inbreeding depression (Greenwood \& Harvey, 1982), whereas males of some mammals are thought to disperse to reduce the probability of kin competition for territories (Bowler \& Benton, 2005). Such pressures to disperse can vary temporally owing to changes in habitat quality associated with density dependence or habitat degradation (Pasinelli et al., 2004). Recent evidence suggests that long-term changes in climate also can mediate these effects on dispersal propensity, potentially by altering food supply (Møller et al., 2006).

New technologies such as daylight-level geolocators have revolutionized the study of seasonal movements in small, passerine birds (Stutchbury et al., 2009; Conklin et al., 2010). Despite the ability of these devices to track individuals across the annual cycle, they are of limited use for studying long-distance dispersal because individuals must be recaptured to acquire data. For migratory birds, the use of endogenous markers such as stable isotopes remains one of the most successful techniques for characterizing long-distance dispersal (Hobson, 2005; Studds et al., 2008). In North America, stable-hydrogen isotope ratios in growing season precipitation $\left(\delta^{2} \mathrm{H}_{P}\right)$ show a strong north-south gradient and correlate strongly with $\delta^{2} \mathrm{H}$ of locally grown tissues, especially in the eastern region of the continent (Hobson \& Wassenaar, 1997). In many species, juvenile birds grow their feathers in the nest and adults moult their flight feathers in late summer on or close to the nesting site (Pyle, 1997). Stable-hydrogen isotope values in feathers $\left(\delta^{2} \mathrm{H}_{F}\right)$ sampled from birds arriving for their first breeding attempt can therefore provide information about dispersal distance from the natal site (Hobson et al., 2004; Studds et al., 2008). Unlike daylight-level geolocators, birds need to be captured only once to obtain information about dispersal.

Bicknell's thrush is a long-distance, Neotropical-Nearctic migratory bird and is one of the rarest breeding passerines in North America, classified as globally 'vulnerable' by the International Union for the Conservation of Nature (IUCN; BirdLife International 2004) and 'threatened' in Canada (COSEWIC, 2009). Bicknell's thrush occupies a restricted, naturally fragmented range throughout its annual cycle and faces multiple threats, including habitat loss on the nonbreeding grounds in Hispaniola (Rimmer et al., 2005a), mountaintop development (Strong et al., 2002), mercury contamination (Rimmer et al., 2005b), commercial forestry (Chisholm \& Leonard, 2008), acid ion deposition (Graveland \& vanderWal, 1996; Hames et al., 2002) and climate change (Rodenhouse et al., 2008). From 1993 to 2003, a core breeding population of Bicknell's thrush in White Mountain National Forest declined by $7 \%$ per year along 40 survey routes and was estimated to contain as few as 4900 individuals (Hale, 2006; King et al., 2008; Lambert et al., 2008). Monitoring in Atlantic Canada from 2002 to 2010 indicated annual declines of 11-16\%, and annual surveys at Mont Gosford, Quebec from 2001 to 2007 revealed a pronounced reduction in the number of sites occupied (COSEWIC, 2009; Campbell, 2011). Quantifying the complete distribution of dispersal distances is likely to be important for refining conservation plans for this species of concern.

We analysed $\delta^{2} \mathrm{H}_{F}$ values of Bicknell's thrush captured during their first breeding season from 1996 to 2005 to evaluate 
patterns of natal dispersal across the majority of the breeding range. We used $\delta^{2} \mathrm{H}_{F}$ values of adult thrushes (i.e. those with at least one previous breeding season) sampled at 25 montane breeding sites in the north-eastern United States and southern Canada as prior information for assigning first-time breeders to their natal site. We calculated the minimum distance that birds could have moved from their natal to first breeding site and fit these data to three common statistical distributions for characterizing the importance of long-distance dispersal: the exponential, Weibull and half-Cauchy. Finally, we assessed differences in the probability of dispersal across the breeding range and through time to understand spatio-temporal variation in how isolated populations of this species are demographically connected.

\section{METHODS}

Bicknell's thrush feather samples were collected from 1996 to 2005 at 25 montane forest breeding sites in the north-eastern United States and south-eastern Canada. These sites were dominated by dense stands of balsam fir (Abies balsamea), red spruce (Picea rubens), white birch (Betula papyrifera) and mountain ash (Sorbus americana) and ranged in elevation from 340 to $1400 \mathrm{~m}$. Birds were captured in mist nets, aged and sexed using criteria from Pyle (1997) and Collier \& Wallace (1989), banded with a unique combination of plastic colour and United States Geological Survey (USGS) or Canadian Wildlife Service (CWS) aluminium leg bands, and released. One tail feather was removed from each bird before release and stored in a glassine envelope for return to the laboratory.

Isotope analyses were performed at the Isotope Hydrology and Ecology Laboratory of Environment Canada in Saskatoon, Canada. Feathers were washed in a 2:1 chloroform/ methanol solution to remove surface oils and air-dried for $48 \mathrm{~h}$. Because feather analysis spanned a substantial time period, two different methods were used to account for the fraction of $\mathrm{H}$ in feathers that exchanges with ambient water vapour. From 1996 to 1999, feather samples were individually equilibrated with steam under controlled conditions prior to isotope analysis as fully described in Wassenaar \& Hobson (2000). From 2000 to 2005, non-exchangeable H was determined by linear regression with previously calibrated in-house keratin standards (Wassenaar \& Hobson, 2003). Feather samples were packed in silver capsules, transferred to an autosampler and pyrolized at $1450^{\circ} \mathrm{C}$ to a single pulse of $\mathrm{H}_{2}$ gas in an elemental analyser (EA3000; EuroVector, Milan, Italy). The $\mathrm{H}_{2}$ sample pulse was then introduced to an isotope ratio mass spectrometer (Micromass Isoprime; Micromass, Manchester, England) via an open-split capillary. We report $\delta^{2} \mathrm{H}_{F}$ of non-exchangeable $\mathrm{H}$ in per mil units $(\%$ o $)$ relative to the Vienna Standard Mean Ocean Water Standard-Standard Light Antarctic Precipitation (VSMOW-SLAP) scale. Because the same keratin laboratory standards were used in both analytical procedures, the results are directly comparable; however, analytical error was higher before 2000 $( \pm 4 \%$ oo compared with after $( \pm 2 \%)$.
We used a model developed by Royle \& Rubenstein (2004) to assign 192 first-time breeders to their natal origin where the likelihood that each $\delta^{2} \mathrm{H}_{F}$ value, $y^{*}$, originates from a given natal location is

$$
f\left(y * \mid \mu_{b}, \sigma_{b}\right)=\frac{1}{\sqrt{2 \pi \sigma_{b}}} \exp \left[-\frac{1}{2 \sigma_{b}^{2}}\left(y *-\mu_{b}\right)^{2}\right]
$$

and $\mu_{\mathrm{b}}$ and $\sigma_{\mathrm{b}}$ are the mean and standard deviation of expected $\delta^{2} \mathrm{H}_{F}$ values in each location. The model thus explicitly incorporates prior information about isotopic variation across the landscape to predict a posterior probability of origin for each $\delta^{2} \mathrm{H}_{F}$ measurement. We used $\delta^{2} \mathrm{H}_{F}$ values of 500 adults to develop prior information about the predicted isotopic composition of breeding sites from which dispersing thrushes could have fledged. Mark-recapture analyses comprising 19 years of data from across the breeding range indicate fairly high annual survival $(\phi=0.68 \pm 0.06 \mathrm{SE}$, 95\% CI: $0.56-0.78$ ) and recapture probabilities (males: $P=0.75 \pm 0.03$ SE, 95\% CI: 0.69-0.80; females: $P=0.62 \pm$ $0.05 \mathrm{SE}, 95 \% \mathrm{CI}: 0.52-0.71$ ), suggesting that adult site fidelity is considerable. Adult $\delta^{2} \mathrm{H}_{F}$ values therefore provided a reasonable approximation of $\delta^{2} \mathrm{H}_{P}$ values at each breeding site. To directly evaluate whether adult $\delta^{2} \mathrm{H}_{F}$ values predicted local isotopic conditions, we acquired independently modelled data on amount-weighted growing season $\delta^{2} \mathrm{H}_{P}$ (Bowen et al., 2005; http://www.waterisotopes.org) and compared them using least-squares regression.

Values of $\delta^{2} \mathrm{H}_{P}$ change across altitude in a similar manner to latitude (Bowen et al., 2005), and the spruce-fir habitat used by thrushes occurs across an elevational gradient throughout the breeding range. To directly examine how potential variation in the altitude of moult could have affected adult $\delta^{2} \mathrm{H}_{F}$ priors, we first calculated the difference in elevation between each montane study site and the lower limit of spruce-fir habitat. We used these data to estimate the expected difference in adult $\delta^{2} \mathrm{H}_{F}$ at each site based on a world-wide trend of a $2.2 \%$ change in $\delta^{2} \mathrm{H}_{P}$ for every $100 \mathrm{~m}$ of altitude (Poage \& Chamberlain, 2001). We then averaged these estimates weighted by the sample size of $\delta^{2} \mathrm{H}_{F}$ at each site. The resulting value thus reflected the maximum expected effect on $\delta^{2} \mathrm{H}_{F}$ priors if adults moulted feathers at the altitudinal extremes of suitable breeding habitat.

Previous research has shown that $\delta^{2} \mathrm{H}_{F}$ values can vary by age in birds, with recently fledged hatch-year individuals and nestlings showing lower values than adults (Cooper's hawk: Meehan et al., 2003; American redstart: Langin et al., 2007; Ovenbird: Haché et al., 2012). Potential explanations for this pattern include isotopic enrichment of the adult water body pool owing to higher metabolic rate and subsequent evaporative cooling (McKechnie et al., 2004), differences in dietary routing of macronutrients by nestlings (Langin et al., 2007) or seasonal variation in the timing of feather growth (Hobson, 2008). This trend could have biased our assessment of natal dispersal because first-time breeders could appear to originate from further north than 
their true site of origin. Prior to making assignments, we therefore evaluated age-related patterns in $\delta^{2} \mathrm{H}_{F}$ by comparing values of adults, first-time breeders and recently fledged hatch-year birds. If necessary, we then adjusted the $\delta^{2} \mathrm{H}_{F}$ value of each first-time breeder to account for any systematic depletion relative to adults.

We evaluated age-related differences in $\delta^{2} \mathrm{H}_{F}$ values using a general linear model with age of each thrush as a fixed effect and made post hoc comparisons among the three ageclasses with Tukey's HSD. We assessed variation in the direction of natal dispersal and differences between males and females by using Pearson's chi-square test. To assess whether the probability of natal dispersal varied spatially across the breeding range and whether it changed across the 10-year study period, we fit a generalized linear model that included latitude of the assigned natal origin and year as fixed effects. Because long-term study sites in Vermont were the only locations monitored for the full 10-year duration of the study, our analysis of temporal change in dispersal probability across the breeding range could be heavily influenced by patterns at these areas. Therefore, we used the approach described above to conduct a separate analysis of annual variation in dispersal probability on the subset of sites in Vermont. Our estimates of temporal change in dispersal probability would be flawed if adult $\delta^{2} \mathrm{H}_{F}$ values used as priors also varied over time. We therefore examined temporal change in adult $\delta^{2} \mathrm{H}_{F}$ by fitting a linear mixed model with year as a fixed effect. We specified random intercepts for breeding region and random slopes for year because feather sample sizes in each region varied over the study. To test the year effect, we fit a second model without this variable and compared the two models with a likelihood ratio test with 1 d.f.

We used ARCGIS software (ESRI, Redlands, CA, USA) to calculate the minimum linear distance that thrushes could have dispersed between the natal area and site of capture during their first breeding attempt. We then fit these data to three statistical distributions commonly used to characterize the relative importance of long-distance dispersal movements: the exponential, Weibull and half-Cauchy (Paradis et al., 2002). The exponential distribution was expected to provide the best fit to the data if natal dispersal showed a geometric decline with increasing distance from the natal area. The half-Cauchy distribution was expected to provide the best fit if the data exhibited a heavy tail of infrequent long-distance natal dispersal movements. Finally, the Weibull distribution was expected to provide the best fit if long-distance dispersal occurred with greater frequency at the right tail than under the half-Cauchy. We fit the data on dispersal distance to each distribution with maximum likelihood and selected the one that provided the best fit by using Akaike's Information Criteria weights (AICw). All analyses were performed with the stats package in program R 2.14 ( $\mathrm{R}$ Development Core Team, 2011) except for the assessment of temporal variation in adult $\delta^{2} \mathrm{H}_{F}$, which was performed with package lme4 (Bates et al., 2011), and distribution fitting, which was performed with the bbmle package (Bolker \& R Development Core Team, 2011).

\section{RESULTS}

The $500 \delta^{2} \mathrm{H}_{F}$ values of adult Bicknell's thrush captured at 25 montane breeding sites from 1996 to 2005 were strongly correlated with amount-weighted growing season $\delta^{2} \mathrm{H}_{P}$ values $\left(r^{2}=0.563, P<0.001, n=500 ;\right.$ Bowen et al., 2005). To improve accuracy of assignment tests, we combined breeding sites with similar adult $\delta^{2} \mathrm{H}_{F}$ values, resulting in six breeding regions from which dispersing thrushes could have originated: the Catskill Mountains of New York $(-57 \pm$ $13 \%$; mean $\pm \mathrm{SD})$, southern Vermont $(-64 \pm 12 \%)$, the Adirondacks and northern New England $(-74 \pm 9 \%$, southern Quebec $(-83 \pm 7 \%)$, New Brunswick $(-89 \pm 18 \%$ ond the Gaspé Peninsula of Quebec $(-100 \pm 10 \%$; Fig. 1). Because $\delta^{2} \mathrm{H}_{F}$ values vary in relation to latitude but not longitude, some montane sites that were grouped into a single breeding region showed considerable longitudinal spread, particularly in northern New England and the Gaspe Peninsula. See Table S1 in Supporting Information for the distribution of adult $\delta^{2} \mathrm{H}_{F}$ sample sizes among the six breeding regions.

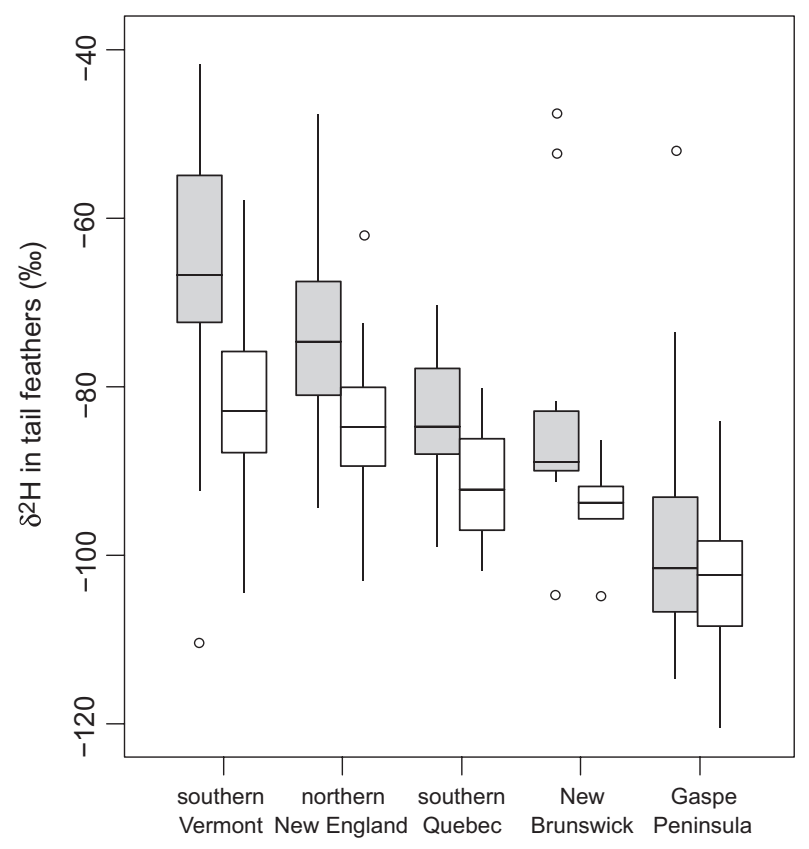

Figure 1 Median, quartiles, range and outliers of $\delta^{2} \mathrm{H}_{F}$ for Bicknell's thrush captured at 25 montane breeding sites across the breeding range in the north-eastern United States and Canada from 1996 to 2005. Sites with similar adult $\delta^{2} \mathrm{H}_{F}$ values were grouped to define six breeding regions (grey bars) that yielded prior information for assigning $\delta^{2} \mathrm{H}_{F}$ values of first-time breeders (white bars) to natal areas. Differences between $\delta^{2} \mathrm{H}_{F}$ of adults and first-time breeders were lowest at northern latitude sites and highest at southern ones, with a minimum difference of $6 \%$ in the north, a mean difference of $12 \%$ and maximum difference of $18 \%$ in the south. 
The mean elevational difference between montane breeding sites and the lower spruce-fir ecotone boundary on each peak was $252 \mathrm{~m}$. Because $\delta^{2} \mathrm{H}_{P}$ values vary world-wide by a mean of $2.2 \%$ for every $100-\mathrm{m}$ change in altitude (Poage \& Chamberlain, 2001), $5.5 \%$ of the variance in adult $\delta^{2} \mathrm{H}_{F}$ priors potentially could be accounted for by elevational differences in feather growth.

Comparison of $\delta^{2} \mathrm{H}_{F}$ values among age-classes revealed substantial variation $\left(F_{3,725}=47.93, P<0.001\right.$; Fig. 1$)$. The $\delta^{2} \mathrm{H}_{F}$ values of adult thrushes were more positive compared with those of both first-time breeders (Tukey's HSD: $P<0.001$ ) and hatch-year birds (Tukey's HSD: $P<0.001$ ). In contrast, first-time breeders and hatch-year birds had similar $\delta^{2} \mathrm{H}_{F}$ values (Tukey's HSD: $P=0.945$ ). On average, $\delta^{2} \mathrm{H}_{F}$ values of first-time breeders were $12 \%$ more negative than those of adults; however, isotopic variation between age groups was more pronounced at the southern compared with the northern part of the breeding range (Fig. 1). The $\delta^{2} \mathrm{H}_{F}$ values of first-time breeders in southern Vermont were lower by $18 \%$ compared with adults, whereas those at the northern end of the breeding range were lower by only $6 \%$. To account for this variation across latitude, we adjusted $\delta^{2} \mathrm{H}_{F}$ values of first-time breeders by the mean $(12 \%)$, northern minimum $(6 \%)$ and southern maximum $(18 \%)$ and assigned birds to their potential natal origin under all three scenarios. Although this approach introduced substantial uncertainty to our analyses, it was preferable to performing a single correction that would yield one estimate of each dispersal parameter and thus fail to reflect the extent of variation in the data. Performing assignments under the $6 \%$ northern minimum and $18 \%$ southern maximum enabled us to depict the complete range of uncertainly in dispersal around the $12 \%$ mean. We report the results of these assignments as the $12 \%$ mean $(6-18 \%$ range).

Of the 192 Bicknell's thrush sampled for $\delta^{2} \mathrm{H}_{F}$ during their first breeding season, 59\% (56-62\%) were classified as dispersing away from their natal region and 41\% (38-44\%) were classified as faithful to their natal region (Fig. 2). See Table S1 in Supporting Information for the distribution of first-time breeder $\delta^{2} \mathrm{H}_{F}$ sample sizes among the six breeding regions. Males and females dispersed with similar frequency (58\% [53-58\%] of males and 56\% [56-61\%] of females; $\left.\chi^{2}=0.04, P=0.998\right)$. The geographical direction of natal dispersal varied depending on the offset used to account for the lower $\delta^{2} \mathrm{H}_{F}$ values of first-time breeders. Based on the $12 \%$ mean offset, there was no discernable pattern in the direction of natal dispersal (47\% northerly and 53\% southerly; $\left.\chi^{2}=0.04, P=0.842\right)$. Under the $6 \%$ minimum offset, southern natal dispersal movements were more common than northern movements (17\% southern and $80 \%$ northern;

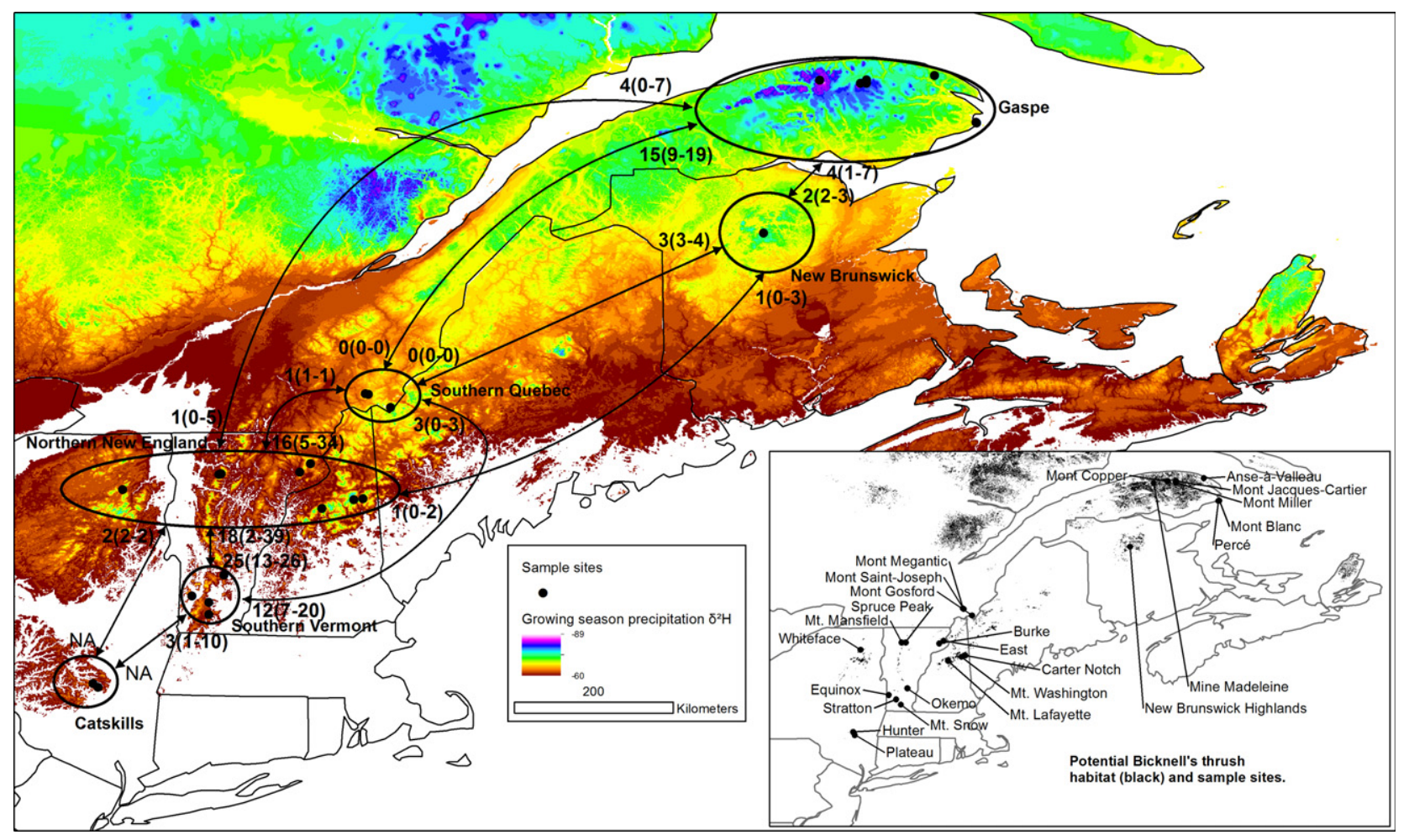

Figure 2 Patterns of natal dispersal among six breeding regions estimated with $\delta^{2} \mathrm{H}_{F}$ for 192 Bicknell's thrushes sampled during their first breeding attempt from 1996 to 2005 . Values show the number of natal dispersers originating from regions linked by arrows. Estimates using each of the three offsets to account for age-related variation in $\delta^{2} \mathrm{H}_{F}$ values across latitude are shown as $12 \%$ mean (6-18\% range). The inset shows potential breeding habitat (black) and locations where birds were sampled; see Table S1 for the distribution of sample sizes among the six breeding regions. 
$\left.\chi^{2}=43.56, P<0.001\right)$. Conversely, using the $18 \%$ maximum offset, the majority of natal dispersal occurred in a northern direction $(79 \%$ northern and $21 \%$ southern $\left.\chi^{2}=33.64, P<0.001\right)$.

Approximately 66\% (63-67\%) of natal dispersal events occurred between geographically adjacent regions (Fig. 2). Exchange of individuals was greatest between sites in southern Vermont and those in northern New England and New York, comprising 40\% (26-44\%) of all dispersal events. In contrast, we detected no natal dispersal among the most northern and southern sites sampled. Thrushes categorized as originating in the Catskills Mountains of southern New York dispersed no further north than northern New England. Similarly, individuals interpreted to have fledged on the Gaspé Peninsula in Quebec and in New Brunswick dispersed only as far south as northern New England. These patterns yielded a curvilinear relationship between natal dispersal probability and the assigned latitude of natal origin, with a strong peak at approximately $46^{\circ} \mathrm{N}$ and steep declines to the north and south under both the $6 \%(z=-5.50$, $P<0.001$; Fig. 3a) and $12 \%$ offsets $(z=-4.30, P<0.001$; Fig. 3b). This latitudinal trend in dispersal probability shifted slightly to the south under the $18 \%$ offset, but the pattern was not statistically significant $(z=-1.53, \quad P=0.126$; Fig. 3c).

The change in natal dispersal probability from 1996 to 2005 depended on the correction factor used to adjust for the lower $\delta^{2} \mathrm{H}_{F}$ values of first-time breeders. Both the $6 \%$ and $12 \%$ offsets resulted in a marked reduction in natal dispersal probability across the 10-year study period, whereas the $18 \%$ offset resulted in a weak increase in dispersal probability. Dispersal probability declined by $38 \%$ using the $6 \%$ offset $(z=-2.95$, $P=0.003$; Fig. $4 \mathrm{a})$ and by $30 \%$ with the $12 \%$ offset $(z=-2.31, P=0.021$; Fig. 4b). Conversely, natal dispersal probability increased by $13 \%$ under the $18 \%$ offset; however, this trend was not statistically significant $(z=-1.00$, $P=0.315$; Fig. 4c). We found qualitatively similar temporal trends in dispersal probability when we analysed only a network of long-term study sites in Vermont, although these patterns were not statistically significant. Dispersal probability declined by $13 \%$ using the $6 \%$ offset $(z=-0.63, P=0.532)$ by $22 \%$ with the $12 \%$ offset $(z=-0.14, P=0.154)$, and increased by $17 \%$ under the $18 \%$ offset $(z=-1.15$, $P=0.249)$. Adult $\delta^{2} \mathrm{H}_{F}$ varied little over the 10 -year study per$\operatorname{iod}\left(\chi^{2}=0.211\right.$, d.f. $\left.=1, P=0.646\right)$, suggesting that temporal changes in natal dispersal probability were not biased by temporal trends in prior information.

Calculation of the minimum linear distance that thrushes could have moved between the assigned natal region and the site of capture 1 year later suggested that the majority of dispersal events were $<200 \mathrm{~km}$ (Fig. 5). The frequency of natal dispersal fell sharply beyond this distance, but it rose again at $500-700 \mathrm{~km}$ from the assigned natal region. The distribution of observed natal dispersal distances was better approximated by a Weibull distribution than by an exponential or half-Cauchy under all three offsets used to account for
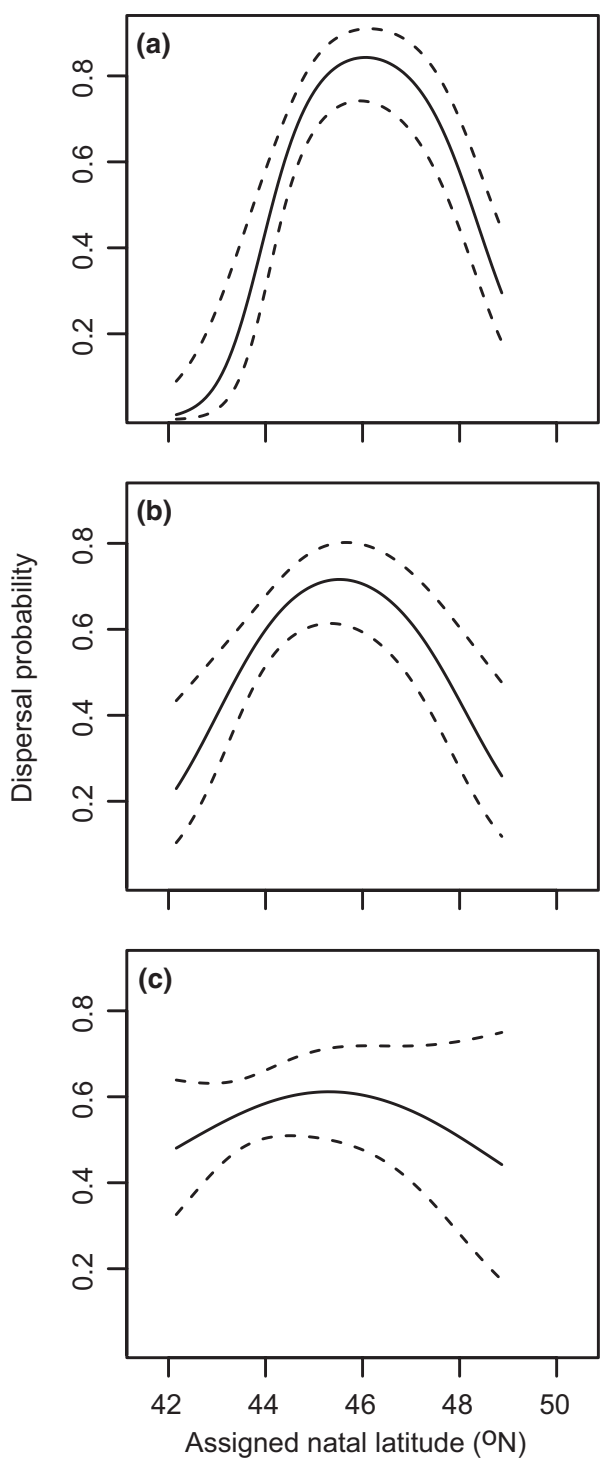

Figure 3 Patterns of natal dispersal probability in relation to latitude of the assigned natal origin for 192 Bicknell's thrush captured at 25 montane breeding sites across the breeding range in the north-eastern United States and Canada from 1996 to 2005 under three different offsets used to account for age-related variation in $\delta^{2} \mathrm{H}_{F}$. Under the (a) $6 \%$ and (b) $12 \%$ offsets, dispersal probability peaked at $45^{\circ} \mathrm{N}$ and declined sharply to the north and south. Under the (c) $18 \%$ offset, dispersal probability peaked further south, but the trend was weaker in comparison. Dashed lines depict 95\% confidence intervals.

age-related variation in $\delta^{2} \mathrm{H}_{F}$ (Table 1). When analysed with the $12 \%$ mean offset, this distribution had a shape parameter of 0.72 and a scale parameter of 134.67. The Weibull distribution conforms precisely to an exponential distribution when the shape parameter $=1$; therefore, a shape parameter $=0.72$ indicated a heavier tail of long-distance dispersal events than expected under the exponential distribution and a lighter one than predicted by the half-Cauchy. 

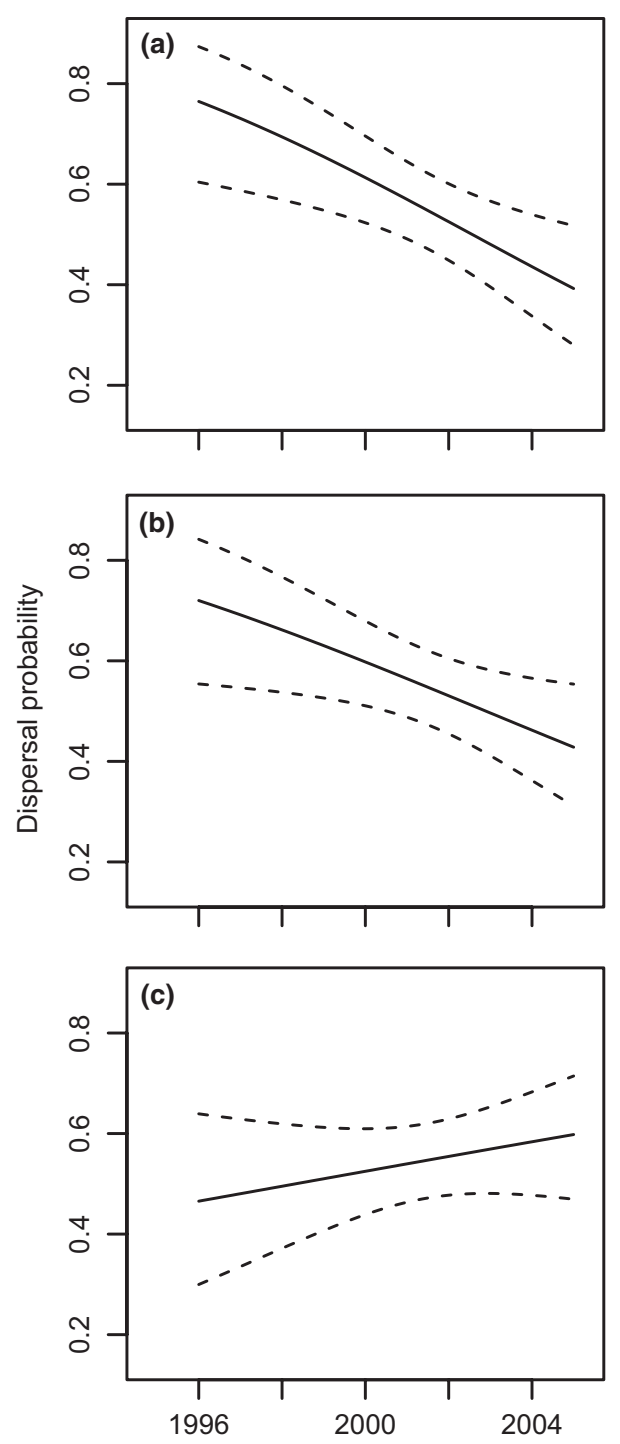

Figure 4 Change in natal dispersal probability from 1996 to 2005 for 192 Bicknell's thrush captured at 25 montane sites across the breeding range in the north-eastern United States and Canada under three different offsets used to account for agerelated variation in $\delta^{2} \mathrm{H}_{F}$. Dispersal probability (a) decreased by $38 \%$ under the $6 \%$ offset (b) by $30 \%$ under the $12 \%$ offset and (c) increased by $13 \%$ under the $18 \%$ offset. Dashed lines depict 95 percent confidence intervals.

\section{DISCUSSION}

The trend that we identified for age-related differences in Bicknell's thrush $\delta^{2} \mathrm{H}_{F}$ values to increase at lower latitudes illustrates the complexity involved in using stable-hydrogen isotopes to assign birds to their natal origin. Despite this potentially confounding pattern, assignment tests correcting for the $12 \%$ mean, $6 \%$ northern and $18 \%$ southern variations in $\delta^{2} \mathrm{H}_{F}$ all suggested that most birds dispersed $<200 \mathrm{~km}$ and near the centre of the breeding range, while comparatively fewer individuals dispersed up to $700 \mathrm{~km}$. Under all three scenarios, a Weibull distribution provided

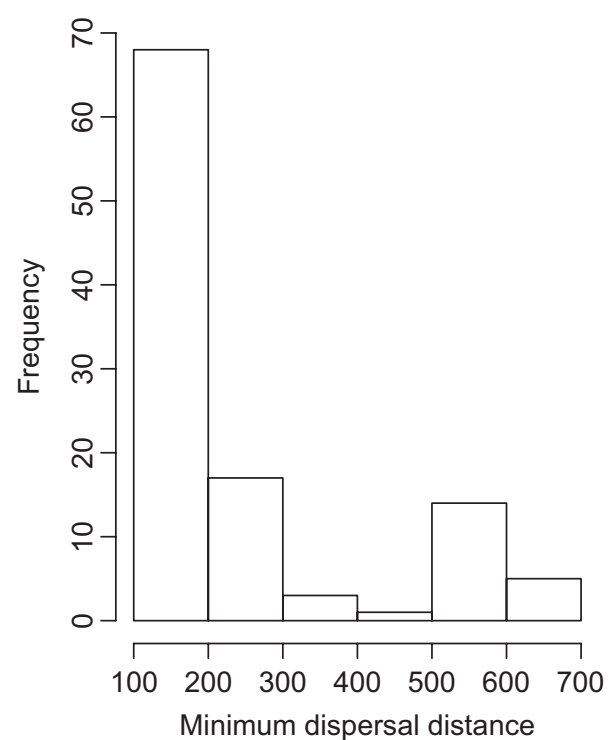

Figure 5 Distribution of natal dispersal distances for 114 Bicknell's thrush captured at 25 montane sites across the breeding range in the north-eastern United States and Canada from 1996 to 2005 under the $12 \%$ mean offset used to account for age-related variation in $\delta^{2} \mathrm{H}_{F}$. Minimum dispersal distance was estimated by measuring the minimum linear distance that thrushes could have moved between the closest possible site in the assigned natal region and the site of capture during the first breeding attempt. A Weibull distribution with a shape parameter of 0.72 and a scale parameter of 134.67 provided the best fit to these data.

the best fit to the data, implying that long-distance dispersal, although infrequent, remains important for characterizing natal dispersal in this species. We also identified discrepancies in natal dispersal patterns under the three different $\delta^{2} \mathrm{H}_{F}$ corrections. Assignments performed using the $6 \%$ offset indicated that over $80 \%$ of thrushes dispersed in a southern direction, whereas the $18 \%$ offset produced the opposite result. When assignments were performed using the $6 \%$ and $12 \%$ offsets, we detected a strong decline in the probability of dispersal across the breeding range over the 10-year duration of the study. In contrast, the $18 \%$ offset supported a weak increase in dispersal probability over time. Collectively, our findings suggest that estimating natal dispersal with $\delta^{2} \mathrm{H}_{F}$ measurements may contribute to understanding the resilience of geographically isolated Bicknell's thrush populations.

Although much of the variation in $\delta^{2} \mathrm{H}_{F}$ between adults and first-time breeders likely arose from age-related physiological or dietary differences (McKechnie et al., 2004; Langin et al., 2007), other sources of error common to both age-classes can also affect assignments made using $\delta^{2} \mathrm{H}_{F}$. Patterns of $\delta^{2} \mathrm{H}_{P}$ at a given location can vary among years owing to differences in both the amount and source of growing season precipitation (Clark \& Fritz, 1997). In addition, $\delta^{2} \mathrm{H}_{P}$ values change in a similar manner with increasing altitude as with increasing latitude (Bowen et al., 2005), and montane 
Table 1 Model fit indices for statistical distributions used to assess the importance of long-distance dispersal to the overall distribution of natal dispersal distances for 114 Bicknell's thrush among six breeding regions in the north-eastern United States and Canada from 1996 to 2005. Distributions were fit for each of the three offsets used to adjust for age-related variation in $\delta^{2} \mathrm{H}_{F}$ across latitude

\begin{tabular}{lllll}
\hline Distribution & d.f. & AIC $c$ & $\Delta \mathrm{AIC} c$ & $\mathrm{AIC} w$ \\
\hline $6 \%$ offset & & & & \\
$\quad$ Weibull & 2 & 2335.3 & 0.0 & 1.0 \\
$\quad$ Exponential & 1 & 2363.3 & 28.0 & $<0.001$ \\
$\quad$ Half-Cauchy & 2 & 5231.8 & 2986.5 & $<0.001$ \\
$12 \%$ offset & & & & \\
$\quad$ Weibull & 2 & 2311.0 & 0.0 & 1.0 \\
Exponential & 1 & 2357.6 & 33.3 & $<0.001$ \\
Half-Cauchy & 2 & 5729.7 & 2972.3 & $<0.001$ \\
$18 \%$ offset & & & & \\
Weibull & 2 & 2381.7 & 0.0 & 1.0 \\
Exponential & 1 & 2404.1 & 22.5 & $<0.001$ \\
Half-Cauchy & 2 & 5420.4 & 3038.8 & $<0.001$ \\
\hline
\end{tabular}

breeding sites where thrushes were captured typically ranged across at least one hundred meters in elevation. Using adult $\delta^{2} \mathrm{H}_{F}$ values as prior information to assign dispersing thrushes to their putative natal areas enabled our analyses to incorporate both sources of variation, and explicit analyses of these errors suggested that they had little effect on our conclusions. Means and standard deviations of adult $\delta^{2} \mathrm{H}_{F}$ priors thus sufficiently encompassed any annual or altitudinal anomalies in $\delta^{2} \mathrm{H}_{P}$ that might have occurred across the 10-year sampling period, potentially leading to more realistic assignments than would have been possible using $\delta^{2} \mathrm{H}_{P}$ measurements to develop prior information.

Research on natal dispersal using conventional markrecapture approaches indicates that most birds disperse < 3-50 km from the natal area, whereas movements of several hundred kilometres are comparatively rare (Paradis et al., 1998; Pasinelli et al., 2004; Winkler et al., 2005). Studies that analysed the distribution of dispersal distances found that a half-Cauchy distribution consistently provided the best fit to the data (Paradis et al., 2002; Winkler et al., 2005). In contrast, we found that natal dispersal patterns of Bicknell's thrush were best approximated by a Weibull distribution. One explanation for this discrepancy is that $\delta^{2} \mathrm{H}_{F}$ values provide poor resolution of locations in close proximity to one another and are therefore cannot describe short-distance dispersal (Bowen et al., 2005). The group of thrushes interpreted to have dispersed up to $200 \mathrm{~km}$ probably included a large number of individuals that moved markedly shorter distances, and homogeneity in their $\delta^{2} \mathrm{H}_{F}$ values may have masked considerable variation in short-distance dispersal. In particular, substantial short-distance dispersal could have occurred longitudinally among montane sites within breeding regions. Our analyses were incapable of detecting such movements because $\delta^{2} \mathrm{H}_{F}$ values only provide information about latitudinal movements. Conversely, the longer distance dispersal events that we recorded, particularly those in excess of $500 \mathrm{~km}$, were ideally estimated with $\delta^{2} \mathrm{H}_{F}$ values and would not have been detected using other available methods such as mark-recapture of banded birds or geolocator tracking. Thus, our limited ability to estimate short-distance dispersal and our enhanced capacity to detect long-distance dispersal were probably equally responsible for the finding that the Weibull distribution provided a better fit than the half-Cauchy.

Some of the best evidence for the existence of long-distance dispersal comes from studies examining geographical variation in neutral genetic markers (Bensch et al., 2002; Trakhtenbrot et al., 2005; Colbeck et al., 2008; Pearce et al., 2009). Most Neotropical-Nearctic migratory birds show little phylogeographical structure across latitude, suggesting that long-distance dispersal events are common enough to prevent genetic differentiation of neutral markers (Lovette et al., 2004; Boulet et al., 2007). In the present study, dispersal events in excess of $200 \mathrm{~km}$ occurred approximately once every generation. Dispersal movements of this distance were concentrated near the central portion of the range in northern New England and the Estrie region of southern Quebec. In contrast, we did not detect dispersal between the northernmost sites in the Gaspé Peninsula and sites at the opposite edge of the breeding range in southern Vermont and the Catskills. These natal dispersal patterns are consistent with measures of genetic relatedness of Bicknell's thrush across the breeding range. Breeding sites in the Catskills and Gaspé Peninsula contain at least two unique haplotypes not found elsewhere, suggesting that gene flow between northern and southern range extremes is rare (Ellison, 2001; Wilson et al., 2004). The general corroboration between our estimates of dispersal distance and the extent of genetic differentiation at range extremes suggests that $\delta^{2} \mathrm{H}_{F}$ values provided a reasonably accurate profile of natal dispersal in this species.

Our estimates of natal dispersal also imply limited demographic connectivity between naturally isolated montane breeding populations of Bicknell's thrush. Long-distance demographic exchange of a few individuals per generation may be sufficient to promote genetic mixing throughout much of the breeding range, but is likely inadequate to sustain strong demographic connectivity (Lowe \& Allendorf, 2010). Although the majority of first-time breeders dispersed within $200 \mathrm{~km}$ of their natal region, these movements peaked near the geographical centre of the breeding range where populations appear to reach their highest abundance. These patterns are consistent with frequency-dependent dispersal and suggest that the majority of natal dispersal events act to connect presently abundant populations where suitable habitat reaches its highest availability.

Low demographic connectivity at broad spatial scales can render isolated populations vulnerable to both temporary and sustained environmental disturbance. Populations weakly connected by dispersal may fluctuate asynchronously because 
of demographic and environmental stochasticity, potentially increasing the risk of local extinction (Peltonen et al., 2002; Jones et al., 2007). Bicknell's thrush is a mid-successional specialist whose habitat is naturally ephemeral owing to disturbances such as fir waves or severe weather events (sensu Sprugel, 1976). Although these disturbances ultimately generate new habitat, they temporarily reduce habitat availability (Lamontagne \& Boutin, 2007) and force birds to disperse in search of breeding sites. Our results suggest that natal dispersal is likely to synchronize and buffer populations against natural disturbances in regions with a substantial network of breeding sites within $200 \mathrm{~km}$. Conversely, breeding sites separated by greater distances, with a low frequency of demographic exchange, may fluctuate out of phase with one another and be at higher risk of local extinction. Long-distance demographic rescue of population sinks by individuals from distant population sources therefore is currently unlikely in this species.

Habitat degradation and loss through anthropogenic disturbance has the potential to indirectly limit natal dispersal. On the breeding grounds in the north-eastern United States and Canada, Bicknell's thrush habitat is directly threatened by commercial timber harvesting, mountaintop recreational development, and energy and communication infrastructure (Strong et al., 2002; Chisholm \& Leonard, 2008; IBTCG et al., 2010). Wet atmospheric deposition of acid ions occurs at a high rate in the northern Appalachians, which may reduce the quantity and quality of calcium-rich prey important to both adults and nestlings (Hames et al., 2002). In addition, climatic warming represents a potential long-term risk to Bicknell's thrush habitat. Modelling efforts suggest that regional warming of $1^{\circ} \mathrm{C}$ could reduce Bicknell's thrush habitat by more than half, and an increase of $2^{\circ} \mathrm{C}$ may be sufficient to eliminate all breeding sites from the Catskill Mountains of New York and most of Vermont (Rodenhouse et al., 2008). Shrinking and further isolation of habitat patches owing to these processes, coupled with ongoing population declines, perhaps partially driven by events in the tropical non-breeding period (Rimmer et al., 2001, 2005a), may reduce natal dispersal rates and lead to a negative feedback loop of further population declines and range contraction.

Our finding that natal dispersal probability declined by 30 $-38 \%$ over 10 years throughout the north-eastern United States and Canada under two of the three $\delta^{2} \mathrm{H}_{F}$ offsets is consistent with independently observed local population declines and extinctions (Atwood et al., 1996; King et al., 2008; Lambert et al., 2008) and may signal that a range-wide population decline is underway. However, we also found that one $\delta^{2} \mathrm{H}_{F}$ offset resulted in a statistically insignificant increase in dispersal probability over the same time frame, a result that limits inference about the link between natal dispersal and observed population declines. Understanding which of these trends is most robust will be important for predicting how Bicknell's thrush populations will cope with natural and anthropogenic disturbances that will undoubtedly limit future habitat availability and suitability. This uncertainty highlights the need for research into the mechanisms underlying age-related variation in $\delta^{2} \mathrm{H}_{F}$. Until this phenomenon is better understood, population viability analyses that explicitly incorporate different scenarios of dispersal are needed to refine conservation plans for Bicknell's thrush.

\section{ACKNOWLEDGEMENTS}

We are grateful to the many field biologists who dedicated countless hours of fieldwork. We also thank the Stratton Mountain Resort, the Mt. Mansfield Company, the East Haven Development Company, the Essex Timber Company, the Forêt Habitée du Mont Gosford and the Sociéte des Établissements de Plein-Air du Québec for valuable logistic support. Funding was provided by the Conservation and Research Foundation, the Davis Conservation Foundation, the Frank and Brinna Sands Foundation, the National Fish and Wildlife Foundation, The Nature Conservancy, the Nuttall Ornithological Club, the Philanthropic Collaborative, the Stratton Foundation, the Stratton Mountain Resort, the Thomas Marshall Foundation, the Wallace Genetic Foundation, a State Wildlife Grant through the Vermont Fish and Wildlife Department, the Vermont Monitoring Cooperative, USDA Forest Service Northeastern Research Station, U.S. Fish and Wildlife Service, the William P. Wharton Trust, friends of the Vermont Center for Ecostudies and the Vermont Institute of Natural Science, and Environment Canada.

\section{REFERENCES}

Atwood, J.L., Rimmer, C.C., McFarland, K.P., Tsai, S.H. \& Nagy, L.R. (1996) Distribution of Bicknell's thrush in New England and New York. Wilson Bulletin, 108, 650-661.

Bates, D., Maechler, M. \& Bolker, B. (2011) lme4: Linear mixed-effects models using S4 classes. R package version 0.999375-42. http://www.CRAN.R-project.org/package $=$ lme4

Bensch, S., Akesson, S. \& Irwin, D.E. (2002) The use of AFLP to find an informative SNP: genetic differences across a migratory divide in willow warblers. Molecular Ecology, 11, 2359-2366.

Bolker, B. \& R Development Core Team (2011). bbmle: Tools for general maximum likelihood estimation. $\mathrm{R}$ package version 1.0.4.1. http://www.CRAN.R-project.org/package= bbmle.

Boulet, M., Couturier, S., Cote, S.D., Otto, R.D. \& Bernatchez, L. (2007) Integrative use of spatial, genetic, and demographic analyses for investigating genetic connectivity between migratory, montane, and sedentary caribou herds. Molecular Ecology, 16, 4223-4240.

Bowen, G.J., Wassenaar, L.I. \& Hobson, K.A. (2005) Global application of stable hydrogen and oxygen isotopes to wildlife forensics. Oecologia, 143, 337-348.

Bowler, D.E. \& Benton, T.G. (2005) Causes and consequences of animal dispersal strategies: relating individual 
behaviour to spatial dynamics. Biological Reviews, 80, 205225.

Campbell, G. (2011) High elevation landbird program. 2010 report. Bird Studies Canada (Atlantic Region), Sackville, NB, Canada.

Chisholm, S.E. \& Leonard, M.L. (2008) Effect of forest management on a rare habitat specialist, the Bicknell's Thrush (Catharus bicknelli). Canadian Journal of Zoology, 86, 217223.

Clark, I.D. \& Fritz, P. (1997) Environmental isotopes in hydrogeology. CRC Press, Boca Raton, FL, USA.

Clobert, J., Danchin, E., Dhondt, A.A. \& Nichols, J.D. (2001) Dispersal. Oxford University Press, Oxford.

Colbeck, G.J., Gibbs, H.L., Marra, P.P., Hobson, K. \& Webster, M.S. (2008) Phylogeography of a widespread North American migratory songbird (Setophaga ruticilla). Journal of Heredity, 99, 453-463.

Collier, B. \& Wallace, G.E. (1989) Aging Catharus thrushes by rectrix shape. Journal of Field Ornithology, 60, 230-240.

Conklin, J.R., Battley, P.F., Potter, M.A. \& Fox, J.W. (2010) Breeding latitude drives individual schedules in a transhemispheric migrant bird. Nature Communications, 1, 1-6.

COSEWIC (2009) COSEWIC assessment and status report on the Bicknell's Thrush (Catharus bicknelli) in Canada. Committee on the Status of Endangered Wildlife in Canada, Ottawa, ON, Canada. http://www.sararegistry.gc.ca/status/ status_e.cfm (accessed 12 December 2011).

Doligez, B., Danchin, E. \& Clobert, J. (2002) Public information and breeding habitat selection in a wild bird population. Science, 297, 1168-1170.

Ellison, W.G. (2001) Population structure and gene flow in two long-distance migrant birds, the Bicknell's Thrush (Catharus bicknelli) and Veery (Catharus fucescens). Doctoral dissertation. SUNY, Albany, NY, USA.

Gaines, M.S. \& McClenaghan, L.R. (1980) Dispersal in small mammals. Annual Review of Ecology and Systematics, 11, 163-196.

Graveland, J. \& vanderWal, R. (1996) Decline in snail abundance due to soil acidification causes eggshell defects in forest passerines. Oecologia, 105, 351-360.

Greenwood, P.J. \& Harvey, P.H. (1982) The natal and breeding dispersal of birds. Annual Review of Ecology and Systematics, 13, 1-21.

Haché, S., Hobson, K.A., Villard, M.-A. \& Bayne, E.M. (2012). Assigning birds to geographic origin using feather hydrogen isotope ratios $\left(\delta^{2} \mathrm{H}\right)$ : importance of year, age, and habitat. Canadian Journal of Zoology, doi: 10.1139/ z2012-039.

Hale, S.R. (2006) Using satellite imagery to model distribution and abundance of Bicknell's Thrush (Catharus bicknelli) in New Hampshire's White Mountains. Auk, 123, 10381051.

Hames, R.S., Rosenberg, K.V., Lowe, J.D., Barker, S.E. \& Dhondt, A.A. (2002) Adverse effects of acid rain on the distribution of the Wood Thrush Hylocichla mustelina in
North America. Proceedings of the National Academy of Sciences USA, 99, 11235-11240.

Hanksi, I. (1999) Metapopulation ecology. Oxford University Press, Oxford.

Hobson, K.A. (2005) Using stable isotopes to trace long-distance dispersal in birds and other taxa. Diversity and Distributions, 11, 157-164.

Hobson, K.A. \& Wassenaar, L.I. (1997) Linking breeding and wintering grounds of neotropical migrant songbirds using stable hydrogen isotopic analysis of feathers. Oecologia, 109, 142-148.

Hobson, K.A., Wassenaar, L.I. \& Bayne, E. (2004) Using isotopic variance to detect long-distance dispersal and philopatry in birds: an example with Ovenbirds and American Redstarts. Condor, 106, 732-743.

Hobson, K.A. (2008) Applying isotopic methods to tracking animal movements. Tracking animal migration with stable isotopes (ed. by K.A. Hobson \& L.I. Wassenaar), pp. 45-78. Academic Press, New York.

IBTCG (2010) A conservation action plan for Bicknell's Thrush (Catharus bicknelli). (ed. by J.A. Hart, C.C. Rimmer R. Dettmers, R.M. Whittam, E.A. Mckinnon \& K.P. Mcfarland). International Bicknell's Thrush Conservation Group. http://www.bicknellsthrush.org.

Jones, J., Doran, P.J. \& Holmes, R.T. (2007) Spatial scaling of avian population dynamics: population abundance, growth rate, and variability. Ecology, 88, 2505-2515.

King, D.I., Lambert, J.D., Buonaccorsi, J.P. \& Prout, L.S. (2008) Avian population trends in the vulnerable montane forests of the Northern Appalachians, USA. Biodiversity and Conservation, 17, 2691-2700.

Koenig, W.D., VanVuren, D. \& Hooge, P.N. (1996) Detectability, philopatry, and the distribution of dispersal distances in vertebrates. Trends in Ecology \& Evolution, 11, 514-517.

Lambert, J.D., King, D.I., Buortaccorsi, J.P. \& Prout, L.S. (2008) Decline of a new Hampshire Bicknell's thrush population, 1993-2003. Northeastern Naturalist, 15, 607-618.

Lamontagne, J.M. \& Boutin, S. (2007) Local-scale synchrony and variability in mast seed production patterns of Picea glauca. Journal of Ecology, 95, 991-1000.

Langin, K.M., Reudink, M.W., Marra, P.P., Norris, D.R., Kyser, T.K. \& Ratcliffe, L.M. (2007) Hydrogen isotopic variation in migratory bird tissues of known origin: implications for geographic assignment. Oecologia, 152, 449-457.

Leibold, M.A., Holyoak, M., Mouquet, N., Amarasekare, P., Chase, J.M., Hoopes, M.F., Holt, R.D., Shurin, J.B., Law, R., Tilman, D., Loreau, M. \& Gonzalez, A. (2004) The metacommunity concept: a framework for multi-scale community ecology. Ecology Letters, 7, 601-613.

Lenormand, T. (2002) Gene flow and the limits to natural selection. Trends in Ecology \& Evolution, 17, 183-189.

Lovette, I.J., Clegg, S.M. \& Smith, T.B. (2004) Limited utility of mtDNA markers for determining connectivity among breeding and overwintering locations in three neotropical migrant birds. Conservation Biology, 18, 156-166. 
Lowe, W.H. \& Allendorf, F.W. (2010) What can genetics tell us about population connectivity? Molecular Ecology, 19, 3038-3051.

McKechnie, A.E., Wolf, B.O. \& del Rio, C.M. (2004) Deuterium stable isotope ratios as tracers of water resource use: an experimental test with rock doves. Oecologia, 140, 191200.

Meehan, T.D., Rosenfield, R.N., Atudorei, V.N., Bielefeldt, J., Rosenfield, L.J., Stewart, A.C., Stout, W.E. \& Bozek, M.A. (2003) Variation in hydrogen stable-isotope ratios between adult and nestling Cooper's Hawks. Condor, 105, 567-572.

Møller, A.P., Flensted-Jensen, E. \& Mardal, W. (2006) Dispersal and climate change: a case study of the Arctic tern Sterna paradisaea. Global Change Biology, 12, 2005-2013.

Nathan, R., Perry, G., Cronin, J.T., Strand, A.E. \& Cain, M. L. (2003) Methods for estimating long-distance dispersal. Oikos, 103, 261-273.

Nocera, J.J., Forbes, G.J. \& Giraldeau, L.A. (2006) Inadvertent social information in breeding site selection of natal dispersing birds. Proceedings of the Royal Society B, 273, 349-355.

Ovaskainen, O. \& Hanski, I. (2004) From individual behavior to metapopulation dynamics: unifying the patchy population and classic metapopulation models. American Naturalist, 164, 364-377.

Paradis, E., Baillie, S.R., Sutherland, W.J. \& Gregory, R.D. (1998) Patterns of natal and breeding dispersal in birds. Journal of Animal Ecology, 67, 518-536.

Paradis, E., Baillie, S.R. \& Sutherland, W.J. (2002) Modeling large-scale dispersal distances. Ecological Modelling, 151, 279-292.

Pasinelli, G., Schiegg, K. \& Walters, J.R. (2004) Genetic and environmental influences on natal dispersal distance in a resident bird species. American Naturalist, 164, 660-669.

Pearce, J.M., Zwiefelhofer, D. \& Maryanski, N. (2009) Meachanisms of population heterogenity among molting common mergansers on Kodiak Island, Alaska: implications for genetic assignments of migratory connectivity. Condor, 111, 283-293.

Peltonen, M., Liebhold, A.M., Bjornstad, O.N. \& Williams, D.W. (2002) Spatial synchrony in forest insect outbreaks: roles of regional stochasticity and dispersal. Ecology, 83, 3120-3129.

Phillips, B.L., Brown, G.P. \& Shine, R. (2010) Life-history evolution in range-shifting populations. Ecology, 91, 1617-1627.

Poage, M.A. \& Chamberlain, C.P. (2001) Emiprical relationships between elevation and the stable isotope composition of precipitation and surface waters: considerations for studies of paleoelevational change. American Journal of Science, 301, 1-15.

Pyle, P. (1997) Identification guide to North American birds. Part 1, Columbidae to Ploceidae. Slate Creek Press, Bolinas, CA, USA.

R Development Core Team (2011) R: A language and environment for statistical computing. $\mathrm{R}$ Foundation for Statistical Computing, Vienna, Austria.
Rimmer, C.C., McFarland, K.P., Ellison, W.G. \& Goetz, J.E. (2001) Bicknell's Thrush (Catharus bicknelli). Birds of North America, No. 592 (ed. by A. Poole \& F. Gill). The Academy of Natural Sciences of Philadelphia and The American Ornithologists' Union, Philadelphia, PA; Washington, DC, USA.

Rimmer, C.C., Townsend, J.M., Townsend, A.K., Fernandez, E.M. \& Almonte, J. (2005a) Avian diversity, abundance, and conservation status in the Macaya Biosphere Reserve of Haiti. Ornitologia Neotropical, 16, 219-230.

Rimmer, C.C., McFarland, K.P., Evers, D.C., Miller, E.K., Aubry, Y., Busby, D. \& Taylor, R.J. (2005b) Mercury concentrations in Bicknell's thrush and other insectivorous passerines in Montane forests of northeastern North America. Ecotoxicology, 14, 223-240.

Rodenhouse, N.L., Matthews, S.N., McFarland, K.P., Lambert, J.D., Iverson, L.R., Prasad, A., Sillett, T.S. \& Holmes, R.T. (2008) Potential effects of climate change on birds of the Northeast. Mitigation and Adaptation Strategies for Global Change, 13, 517-540.

Royle, J.A. \& Rubenstein, D.R. (2004) The role of species abundance in determining breeding origins of migratory birds with stable isotopes. Ecological Applications, 14, 17801788 .

Semlitsch, R.D. (2008) Differentiating migration and dispersal processes for pond-breeding amphibians. Journal of Wildlife Management, 72, 260-267.

Sprugel, D.G. (1976) Dynamic structure of wave-regenerated Abies balsamea forests in the north-eastern United States. Journal of Ecology, 64, 889-911.

Strong, A.M., Rimmer, C.C., McFarland, K.P. \& Hagen, K. (2002) Effects of mountain resorts on wildlife. Vermont Law Review, 26, 689-716.

Studds, C.E., Kyser, T.K. \& Marra, P.P. (2008) Natal dispersal driven by environmental conditions interacting across the annual cycle of a migratory songbird. Proceedings of the National Academy of Sciences USA, 105, 2929-2933.

Stutchbury, B.J.M., Tarof, S.A., Done, T., Gow, E., Kramer, P.M., Tautin, J., Fox, J.W. \& Afanasyev, V. (2009) Tracking long distance songbird migration by using geolocators. Science, 323, 896.

Trakhtenbrot, A., Nathan, R., Perry, G. \& Richardson, D.M. (2005) The importance of long-distance dispersal in biodiversity conservation. Diversity and Distributions, 11, 173181.

Wassenaar, L.I. \& Hobson, K.A. (2000) Improved method for determining the stable-hydrogen isotopic composition $(\delta \mathrm{D})$ of complex organic materials of environmental interest. Environmental Science \& Technology, 34, 2354-2360.

Wassenaar, L.I. \& Hobson, K.A. (2003) Comparative equilibration and online technique for determination of nonexchangeable hydrogen of keratins for use in animal migration studies. Isotopes in Environmental and Health Studies, 39, 211-217.

Wiegand, T., Moloney, K.A., Naves, J. \& Knauer, F. (1999) Finding the missing link between landscape structure and 
population dynamics: a spatially explicit perspective. American Naturalist, 154, 605-627.

Wilson, P., McEachen, T., Aubry, Y. \& Seutin, G. (2004) Conservation genetics of Bicknell's and Grey-cheeked thrush. 122nd American Ornithologists' Union meeting and annual meeting of the Society of Canadian Ornithologists, Québec, QC, Canada.

Winkler, D.W., Wrege, P.H., Allen, P.E., Kast, T.L., Senesac, P., Wasson, M.F. \& Sullivan, P.J. (2005) The natal dispersal of tree swallows in a continuous mainland environment. Journal of Animal Ecology, 74, 1080-1090.

\section{SUPPORTING INFORMATION}

Additional Supporting Information may be found in the online version of this article:

Table S1 Sample sizes of stable-hydrogen isotope values in Bicknell's thrush tail feathers $\left(\delta^{2} \mathrm{H}_{F}\right)$ used to assess natal dispersal patterns among six breeding regions in the northeastern United States and southern Canada from 1996-2005.

As a service to our authors and readers, this journal provides supporting information supplied by the authors. Such materials are peer-reviewed and may be re-organized for online delivery, but are not copy-edited or typeset. Technical support issues arising from supporting information (other than missing files) should be addressed to the authors.

\section{BIOSKETCHES}

All co-authors work on the ecology, conservation and management of wildlife. Colin Studds and Peter Marra from the Smithsonian Conservation Biology Institute and Keith Hobson and Leonard Wassenaar from Environment Canada have been pioneers in the development and use of stable isotopes as biomarkers to investigate wildlife population connectivity. Kent McFarland, Christopher Rimmer and Yves Aubry helped organize the International Bicknell's Thrush Conservation Group (www.bicknellsthrush.org), a group of scientists and land managers who's aim is to develop a broad-based, scientifically sound approach to conserve Bicknell's thrush by incorporating research, population monitoring and management action.

Author contributions: K.P.M and C.C.R conceived the study; K.P.M., C.C.R. and Y.A. collected the data; K.A.H. and L.I. W. performed isotope analyses; C.E.S. performed statistical analyses with input from K.P.M., K.A.H. and P.P.M.; C.E.S. led the writing with help from K.P.M. and feedback from C. C.R., K.A.H., P.P.M., and L.I.W.

Editor: David Richardson 